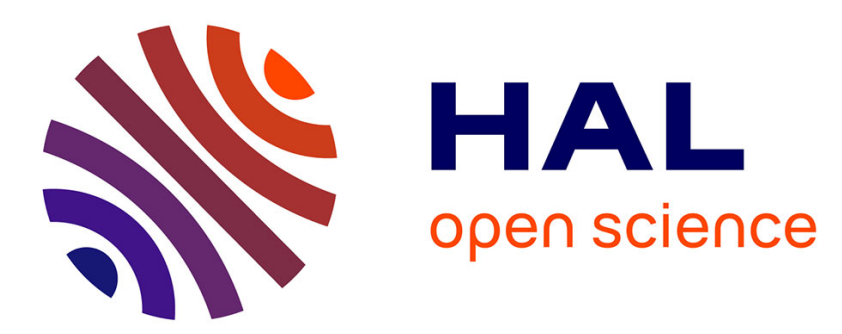

\title{
Vibration of multilayered beams using sinus finite elements with transverse normal stress.
}

\author{
P. Vidal, O. Polit
}

\section{To cite this version:}

P. Vidal, O. Polit. Vibration of multilayered beams using sinus finite elements with transverse normal stress.. Composite Structures, 2010, 92 (6), pp.1524-1534. 10.1016/j.compstruct.2009.10.009 . hal01366979

\section{HAL Id: hal-01366979 \\ https://hal.science/hal-01366979}

Submitted on 5 Jan 2018

HAL is a multi-disciplinary open access archive for the deposit and dissemination of scientific research documents, whether they are published or not. The documents may come from teaching and research institutions in France or abroad, or from public or private research centers.
L'archive ouverte pluridisciplinaire HAL, est destinée au dépôt et à la diffusion de documents scientifiques de niveau recherche, publiés ou non, émanant des établissements d'enseignement et de recherche français ou étrangers, des laboratoires publics ou privés. 


\title{
Vibration of multilayered beams using sinus finite elements with transverse normal stress
}

\author{
P. Vidal *, O. Polit \\ LEME, Université Paris Ouest, 50 rue de Sèvres, 92410 Ville d'Avray, France
}

\begin{abstract}
A B S T R A C T
A family of sinus models is presented for the analysis of laminated beams in the framework of free vibration. A three-noded finite element is developed with a sinus distribution with layer refinement. The transverse shear strain is obtained by using a cosine function avoiding the use of shear correction factors. This kinematic accounts for the interlaminar continuity conditions on the interfaces between the layers, and the boundary conditions on the upper and lower surfaces of the beam. A conforming FE approach is carried out using Lagrange and Hermite interpolations. It is important to notice that the number of unknowns is independent of the number of layers. Vibration mechanical tests for thin and thick laminated and sandwich beams are presented in order to evaluate the capability of these new finite elements to give accurate results with respect to elasticity or finite element reference solutions. Both convergence velocity and accuracy are discussed and these new finite elements yield very accurate results at a low computational cost for various boundary conditions. In particular, the two models including the transverse normal effect have the capability to take into account the thickness mode shape.
\end{abstract}

\section{Introduction}

Considering the increasing applications of composite and sandwich structures in the industrial field due to their high specific strength and stiffness, it is important to develop advanced and accurate models to design. In this framework, accurate knowledge of deflection and stresses is required to take into account effects of the transverse shear deformation due to the low ratio of transverse shear modulus to axial modulus, or failure due to delamination... In fact, they can play an important role on the behaviour of structures in services, which leads to evaluate precisely their influence on local stress fields in each layer or on natural frequencies.

The aim of this paper is to construct and evaluate a family of finite elements to analyze laminated beams in elasticity in relation to small displacements, so as to obtain the accurate predictions of frequencies in free vibration case. In particular, we put the emphasis on the influence of transverse normal effects, especially for very thick beams.

According to published research, various theories in vibrational mechanics for composite or sandwich structures (beams and plates for the present scope) have been developed. The following classification is associated with the dependency on the number of degrees of freedom (dofs) with respect to the number of layers:

\footnotetext{
* Corresponding author. Tel./fax: +33140979823.

E-mail address: philippe.vidal@u-paris10.fr (P. Vidal).
}

- The Equivalent Single Layer approach (ESL): the number of unknowns is independent of the number of layers, but the transverse shear and normal stresses continuity on the interfaces between layers are often violated. The first work for one-layer isotropic plates was proposed in [1]. Then, we can distinguish the classical laminate theory [2] (it is based on the EulerBernoulli hypothesis and leads to inaccurate results for composites and moderately thick beams, because both transverse shear and normal strains are neglected), the first order shear deformation theory [3-9], and higher order theories [10]. In this later, hyperbolic [11], exponential [11,12], parabolic [13], cubic [14-16,13,17], polynomial functions [18-20] are used in the expansion of the in-plane displacement component. Some of these theories also include the transverse normal effect with non-constant polynomial expressions of the out-of-plane displacement $[21,19,22,17]$. Most of these approaches are based on a displacement formulation; nevertheless, mixed formulations are also carried out. In this framework, finite element $[14,21,10,16,13]$, analytical $[11,15,17,12]$, or state-space $[5,23]$ solution are carried out.

- The Layerwise approach (LW): The number of dofs depends on the number of layers. This theory aims at overcoming the restriction of the ESL concerning the discontinuity of outof-plane stresses on the interface layers. This approach was introduced in [24,25], and also used in [26-28]. In recent contributions, various orders of expansion for the in-plane displacement are chosen: trigonometric [29], linear [30], quadratic 
[31], cubic [32,33]. Some of them take into account the transverse normal effect [32] with a mixed approach. Special studies dedicated to the sandwich beam can be cited $[34,35]$. The transverse displacement is constant in faces and quadratic in core. See also [36].

In this framework, refined models have been developed in order to improve the accuracy of ESL models avoiding the additional computational cost of LW approach. Based on physical considerations and after some algebraic transformations, the number of unknowns becomes independent of the number of layers. [27] has extended the work of [37] for symmetric laminated composites with arbitrary orientation and a quadratic variation of the transverse stresses in each layer. A family of models, denoted zig-zag models, was first employed in [38], then in [39,31,40]. More recently, it was also modified and improved by some authors [41-46] with different order of kinematics assumptions, taking into account the transverse normal strain.

This above literature deals with only some aspects of the broad research activity about models for layered structures and corresponding finite element formulations. An extensive assessment of different approaches has been made in [47-51]. About the particular point of the evaluation of transverse normal stresses, see $[52,53]$. A survey of developments in the vibration analysis of laminated composite beams is compiled in [54], see also [55].

In this work, a family of finite elements for rectangular laminated beam analysis is built, in order to have a low cost tool, efficient and simple to use. In fact, our approach is associated with the ESL theory. These elements are totally free of shear locking and are based on a refined shear deformation theory [56] avoiding the use of shear correction factors for laminates. Our elements are based on the sinus model [57] and the important feature is the capability of the model to include the transverse normal effect. So, the transverse displacement is written under a second order expansion which avoids the Poisson locking mechanism (see [58]). For the in-plane displacement, the double superposition hypothesis from [59] is used: three local functions are added to the sinus model. Finally, this process yields to only six or seven independent generalized displacements. It should be noted that all interface and boundary conditions are exactly satisfied for displacements and transverse shear stress. Therefore, this approach takes into account physical meaning.

As far as the interpolation of these finite elements is concerned, our elements are $\mathrm{C}^{0}$-continuous except for the transverse displacement associated with bending which is $\mathrm{C}^{1}$.

In this article, the mechanical formulation for the different models is described. For each of these approaches, the associated finite element is given. They are illustrated by numerical tests which have been performed upon various laminated and sandwich beams. A parametric study is given to show the effects of different parameters such as length to thickness ratio and number of degrees of freedom. The accuracy of computations are also evaluated by comparisons with an exact 2D elasticity solution, two-dimensional computations using commercial finite element software, three other sinus models [60] and also results available in literature. Different boundary conditions are also evaluated. Through these examples, the influence of transverse normal effect is highlighted.

\section{Resolution of the mechanical problem}

\subsection{The governing equations}

Let us consider a beam occupying the domain $\mathscr{B}=[0, L] \times$ $\left[-\frac{h}{2} \leqslant z \leqslant \frac{h}{2}\right] \times\left[-\frac{b}{2} \leqslant x_{2} \leqslant \frac{b}{2}\right]$ in a Cartesian coordinate $\left(x_{1}, x_{2}, z\right)$.

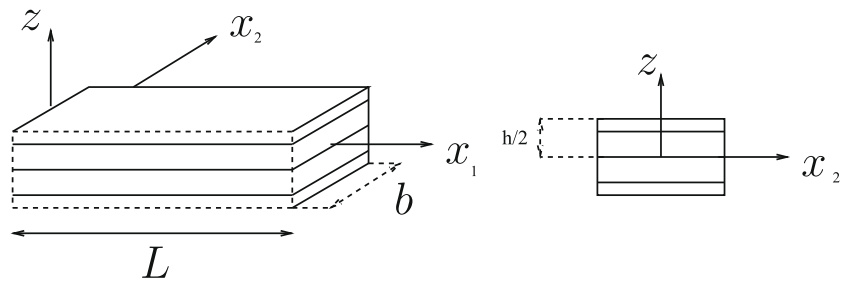

Fig. 1. The laminated beam and coordinate system.

The beam has a rectangular uniform cross section of height $h$, width $b$ and is assumed to be straight. The beam is made of NClayers of different linearly elastic materials. Each layer may be assumed to be orthotropic in the beam axes. The $x_{1}$ axis is taken along the central line of the beam whereas $x_{2}$ and $z$ are the two axes of symmetry of the cross section intersecting at the centroid, see Fig. 1 . As shown in this figure, the $x_{2}$ axis is along the width of the beam. This work is based upon a displacement approach for geometrically linear elastic beams.

\subsubsection{Constitutive relation}

Each layer of the laminate is assumed to be orthotropic. Using matrix notation, the elastic stress-strain law of the kth layer is given by:

$$
\left[\begin{array}{l}
\sigma_{11}^{(k)} \\
\sigma_{33}^{(k)} \\
\sigma_{13}^{(k)}
\end{array}\right]=\left[\begin{array}{ccc}
C_{11}^{(k)} & C_{13}^{(k)} & 0 \\
& C_{33}^{(k)} & 0 \\
\text { symm } & & C_{55}^{(k)}
\end{array}\right]\left[\begin{array}{c}
\varepsilon_{11}^{(k)} \\
\varepsilon_{33}^{(k)} \\
\varepsilon_{13}^{(k)}
\end{array}\right] \text { i.e. }\left[\sigma^{(k)}\right]=\left[C^{(k)}\right]\left[\varepsilon^{(k)}\right]
$$

where we denote: the stress tensor $[\sigma]$; the strain tensor $[\varepsilon] ; C_{i j}$ are the three-dimensional stiffness coefficients.

\subsubsection{The weak form of the boundary value problem}

Using the above matrix notation and for admissible virtual displacement $\vec{u}^{*} \in U^{*}$, the variational principle is given by:

find $\vec{u} \in U$ (space of admissible displacements) such as:

$$
\begin{aligned}
& -\int_{\mathscr{B}}\left[\varepsilon\left(\vec{u}^{*}\right)\right]^{T}[\sigma(\vec{u})] d \mathscr{B}+\int_{\mathscr{B}}\left[u^{*}\right]^{T}[f] d \mathscr{B}+\int_{\partial_{\mathscr{B}}}\left[u^{*}\right]^{T}[F] d \partial \mathscr{B} \\
& =\int_{\mathscr{B}} \rho\left[u^{*}\right]^{T}[\ddot{u}] d \mathscr{B} \quad \forall \vec{u}^{*} \in U^{*}
\end{aligned}
$$

where $[f]$ and $[F]$ are the prescribed body and surface forces applied on $\partial \mathscr{B}_{F} . \varepsilon\left(\vec{u}^{*}\right)$ is the virtual strain, and $\rho$ is the mass density.

The variational principle Eq. (2) provides a convenient framework to develop finite element approximations.

\subsection{The displacement field for laminated beams}

Based on the sinus function (see $[61,62]$ ), two models which take into account the transverse normal deformation are presented in this section.

In the following, we can distinguish:

- The refined sinus model with 2 nd order expansion for the transverse displacement (denoted SinRef-6p) where the refinement is added in each layer.

- The refined sinus model (denoted SinRef-7p) with one more unknown than the previous one for the in-plane displacement.

They are based on both

- Various works on beams, plates and shells, cf. Ref. $[63,56,57,61,64-66]$ concerning the refined theory.

- The so-called 1,2-3 double-superposition theory developed by $\mathrm{Li}$ and Liu [59]. 
It also follows works about local-global approach studied in [67-69].

These refined models (see [60]) take into account the continuity conditions between layers of the laminate for both displacements and transverse shear stress, and the free conditions on the upper and lower surfaces owing to the Heaviside function.

The kinematics of the two models ([70]) is assumed to be of the following particular form:

(1) The SinRef-6p model:

$$
\left\{\begin{array}{c}
u_{1}\left(x_{1}, x_{2}, z\right)=u\left(x_{1}\right)-z w_{0}\left(x_{1}\right)_{, 1}+f(z)\left(\omega_{3}\left(x_{1}\right)+w_{0}\left(x_{1}\right)_{, 1}\right) \\
\quad+\sum_{k=1}^{N C}\left(\bar{u}_{l o c}^{(k)}\left(x_{1}, z\right)+\hat{u}_{l o c}^{(k)}\left(x_{1}, z\right)\right)\left(H\left(z-z_{k}\right)-H\left(z-z_{k+1}\right)\right) \\
u_{3}\left(x_{1}, x_{2}, z\right)=w_{0}\left(x_{1}\right)+z w_{1}\left(x_{1}\right)+z^{2} w_{2}\left(x_{1}\right)
\end{array}\right.
$$

(2) The SinRef-7p model:

$$
\left\{\begin{array}{c}
u_{1}\left(x_{1}, x_{2}, z\right)=u\left(x_{1}\right)+z v\left(x_{1}\right)+f(z)\left(\omega_{3}\left(x_{1}\right)+w_{0}\left(x_{1}\right)_{, 1}\right) \\
\quad+\sum_{k=1}^{N C}\left(\bar{u}_{l o c}^{(k)}\left(x_{1}, z\right)+\hat{u}_{l o c}^{(k)}\left(x_{1}, z\right)\right)\left(H\left(z-z_{k}\right)-H\left(z-z_{k+1}\right)\right) \\
u_{3}\left(x_{1}, x_{2}, z\right)=w_{0}\left(x_{1}\right)+z w_{1}\left(x_{1}\right)+z^{2} w_{2}\left(x_{1}\right)
\end{array}\right.
$$

where $H$ is the Heaviside function defined by

$$
\begin{cases}H\left(z-z_{k}\right)=1 & \text { if } z \geqslant z_{k} \\ H\left(z-z_{k}\right)=0 & \text { if not }\end{cases}
$$

In the classic approach, $w_{0}$ is the bending deflection following the $z$ direction, while $u$ is associated with the uniform extension of the cross section of the beam along the central line, and $\omega_{3}$ is the shear bending rotation around the $x_{2}$ axis.

It should be noted that the kinematic constraint concerning the relation with the derivative of the deflection $\left(v\left(x_{1}\right)=-w_{0}\left(x_{1}\right)_{1}\right)$ is relaxed in the SinRef-7p model.

The local functions $\bar{u}_{l o c}^{(k)}$ and $\hat{u}_{l o c}^{(k)}$ based on the Legendre polynomial can be written as:

$\left\{\begin{array}{l}\bar{u}_{l o c}^{(k)}\left(x_{1}, z\right)=\zeta_{k} u_{31}^{k}\left(x_{1}\right)+\left(-\frac{1}{2}+\frac{3 \zeta_{k}^{2}}{2}\right) u_{32}^{k}\left(x_{1}\right) \\ \hat{u}_{l o c}^{(k)}\left(x_{1}, z\right)=\left(-\frac{3 \zeta_{k}}{2}+\frac{\zeta_{k}^{3}}{2}\right) u_{33}^{k}\left(x_{1}\right)\end{array}\right.$

The coordinate system is precised on Fig. 2. A non-dimensional coordinate is introduced by: $\zeta_{k}=a_{k} z-b_{k}, a_{k}=\frac{2}{z_{k+1}-z_{k}}, b_{k}=\frac{z_{k+1}+z_{k}}{z_{k+1}-z_{k}}$.

In the context of the sinus model, we have:

$f(z)=\frac{h}{\pi} \sin \frac{\pi z}{h}$

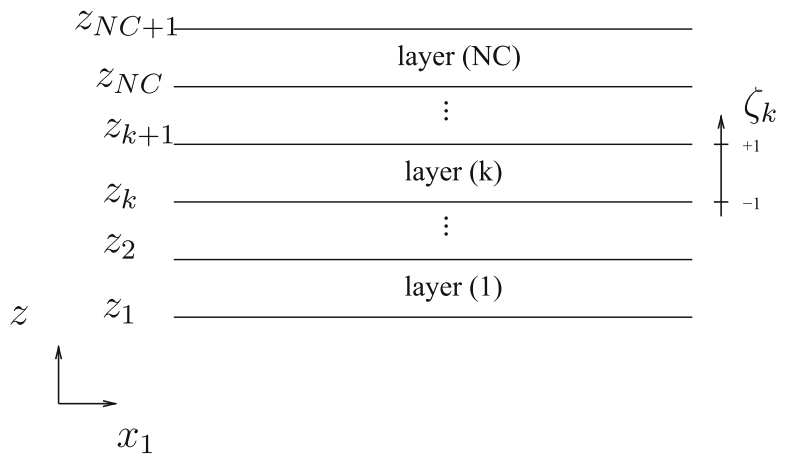

Fig. 2. Coordinate system of laminated beam. and the derivative of this function will represent the transverse shear strain distribution due to bending.

Remarks: from Eq. (3), classical beam models can be deduced without the local functions and the two higher-order terms of the transverse displacement:

- Euler-Bernoulli

$$
f(z)=0
$$

- Timoshenko

$$
f(z)=z
$$

- Sinus model

$$
f(z)=\frac{h}{\pi} \sin \frac{\pi z}{h}
$$

Hence, it is not necessary to introduce transverse shear correction factors.

At this stage, $3 \times N C+5$ and $3 \times N C+6$ generalized displacements are included in Eqs. (3) and (6) (sinRef-6p model) and Eqs. (4) and (6) (sinRef-7p model), respectively.

The following part is dedicated to the obtention of relations between kinematic unknowns from

- Lateral boundary conditions.

- Interlaminar continuity conditions (displacement, transverse shear stress).

In the following, we only focus on the SinRef-7p model. The same procedure can be carried out for the SinRef- $6 \mathrm{p}$ model by setting $v\left(x_{1}\right)=-w_{0}\left(x_{1}\right)_{1}$.

\subsubsection{Continuity conditions and free conditions}

From the displacement field Eq. (4), some continuity conditions on displacements and interlaminar stress must be imposed. For an interface layer $k \in\{2, \ldots, N C\}$, we have

- Displacement continuity conditions as in [67] i.e.:

$$
\begin{array}{ll}
\bar{u}_{l o c}^{(k)}\left(x_{1}, z_{k}\right)=\bar{u}_{l o c}^{(k-1)}\left(x_{1}, z_{k}\right) & k=2, \ldots, N C \\
\hat{u}_{l o c}^{(k)}\left(x_{1}, z_{k}\right)=\hat{u}_{l o c}^{(k-1)}\left(x_{1}, z_{k}\right) & k=2, \ldots, N C
\end{array}
$$

- Transverse shear stress continuity between two adjacent layers:

$$
\sigma_{13}^{(k)}\left(x_{1}, z_{k}^{+}\right)=\sigma_{13}^{(k-1)}\left(x_{1}, z_{k}^{-}\right) \quad k=2, \ldots, N C
$$

So, $3 \times(N C-1)$ conditions are imposed, which allow to reduce the number of unknowns to nine generalized displacements.

Free conditions of the transverse shear stress on the upper and lower surfaces must also be verified. So, we have:

$\sigma_{13}^{(1)}\left(x_{1}, z=-\frac{h}{2}\right)=0 \quad$ and $\quad \sigma_{13}^{(N C)}\left(x_{1}, z=\frac{h}{2}\right)=0$

Finally, the number of generalized displacements is reduced to seven, which is independent of the number of layers.

\subsubsection{Relation between the generalized displacements}

Using the displacement notation introduced in Eq. (6), the conditions Eqs. (8)-(11) can be written under a linear system which yields relations between $u_{31}^{j}(j \neq 1), u_{32}^{j}, u_{33}^{j}, j=1, \ldots, N C$ and $u_{31}^{1}$. This relation can be written under the following form:

$$
\begin{aligned}
u_{3 i}^{j}\left(x_{1}\right)= & \beta_{i}^{j}\left(\omega_{3}\left(x_{1}\right)+w_{0}\left(x_{1}\right)_{, 1}\right)+\eta_{i}^{j}\left(v\left(x_{1}\right)+w_{0}\left(x_{1}\right)_{, 1}\right)+\delta_{i}^{j} u_{31}^{1}\left(x_{1}\right) \\
+ & \lambda_{i}^{j} w_{1}\left(x_{1}\right)_{, 1}+\mu_{i}^{j} w_{2}\left(x_{1}\right)_{, 1}, j=1, \ldots, N C \quad i=1,2,3 \\
& \quad \text { with } \delta_{1}^{1}=1, \beta_{1}^{1}=\eta_{1}^{1}=\lambda_{1}^{1}=\mu_{1}^{1}=0
\end{aligned}
$$


where $\beta_{i}^{j}, \delta_{i}^{j}, \lambda_{i}^{j}, \mu_{i}^{j}$, and $\eta_{i}^{j}(i=1,2,3)$ are the coefficients deduced from this linear system.

Finally, the seven unknowns become $u, w_{0}, \omega_{3}, v, w_{1}, w_{2}$ and $u_{31}^{1}$. It is to be noted that the SinRef-6p model involves six unknowns $\left(u, w_{0}, \omega_{3}, w_{1}, w_{2}\right.$ and $\left.u_{31}^{1}\right)$.

\subsubsection{Matrix expression for the weak form}

From the weak form of the boundary value problem Eq. (2), and using Eq. (14), an integration throughout the cross section is performed analytically in order to obtain an unidimensional formulation. Therefore, the right term of Eq. (2) can be written under the following:

$$
\begin{gathered}
\int_{\mathscr{B}} \rho\left[u^{*}\right]^{T}[\ddot{u}] d \mathscr{B}=\int_{0}^{L}\left[\mathscr{E}_{u}^{*}\right]^{T}[m]\left[\ddot{\mathscr{E}}_{u}\right] d x_{1} \\
\text { with }[m]=\int_{\Omega} \rho\left[F_{u}(z)\right]^{T}\left[F_{u}(z)\right] d \Omega
\end{gathered}
$$

where $\Omega$ represents the cross section $\left[-\frac{h}{2} \leqslant z \leqslant \frac{h}{2}\right] \times\left[-\frac{b}{2} \leqslant x_{2} \leqslant \frac{b}{2}\right]$,

$$
\begin{aligned}
{[u]^{T} } & =\left[F_{u}(z)\right]\left[\mathscr{E}_{u}\right] \quad \text { with }\left[\mathscr{E}_{u}\right]^{T} \\
& =\left[u: w_{0} w_{0,1} \vdots \omega_{3} \vdots u_{31}^{1} \vdots v: w_{1} w_{1,1} \vdots w_{2} w_{2,1}\right]
\end{aligned}
$$

and $\left[F_{u}(z)\right]$ is a matrix which only depends on the transverse displacement component and is deduced from Eqs. (12), (3) and (4).

Same calculations for the first left term of Eq. (2) are carried out to calculate the stiffness matrix, it is detailed in Appendix A.

In Eq. (13), the matrix $[\mathrm{m}]$ is the integration throughout the cross section of the material characteristics of the beam. The interest of the choice of the Legendre polynomials can be emphasized in the calculation of the matrix $[\mathrm{m}]$ owing to their properties of orthogonality.

\subsection{The finite element approximation}

This section is dedicated to the finite element approximation of the generalized displacement, see matrices $\left[\mathscr{E}_{u}\right]$, and $\left[\mathscr{E}_{u}^{*}\right]$, Eq. (14). It is briefly described, and the reader can obtain a detailed description in $[57,60]$.

\subsubsection{The geometric approximation}

Given the displacement field constructed above for sandwich and laminated beams, a corresponding finite element is developed in order to analyze the behaviour of laminated beam structures under combined loads. Let us consider the eth element $L_{e}^{h}$ of the mesh $\cup L_{e}^{h}$. This element has three nodes, denoted by $\left(g_{j}\right)_{j=1,2,3}$, see Fig. 3 . A point with coordinate $x_{1}$ on the central line of the beam will be as follows:

$x_{1}(\xi)=\sum_{j=1}^{2} N l_{j}(\xi) x_{1}^{e}\left(g_{j}\right)$

where $\mathrm{Nl}_{j}(\xi)$ are Lagrange linear interpolation functions and $x_{1}^{e}\left(g_{j}\right)$ are Cartesian coordinates (measured along the $x_{1}$ axis) of the node $g_{j}$ of the element $L_{e}^{h} . \xi$ is an isoparametric or reduced coordinate and its variation domain is $[-1,1]$.

\subsubsection{Interpolation for the beam element}

The finite element approximations of the assumed displacement field components are hereafter symbolically written as $u_{i}^{h}\left(x_{1}, x_{2}, z\right)$ where the superscript $h$ refers to the mesh $\cup L_{e}^{h}$.

From the kinematics (see Eq. (4)), the transverse displacement $w_{0}^{h}$ must be $C^{1}$-continuous; whereas the rotation $\omega_{3}^{h}$, the extension displacement $u^{h}, v^{h}$ and $u_{31}^{1}$ can be only $C^{0}$-continuous. Therefore, the generalized displacement $w_{0}^{h}, w_{1}^{h}$, and $w_{2}^{h}$ are interpolated by the Hermite cubic functions $N h_{j}(\xi)$.

According to the transverse shear locking phenomena, the other shear bending generalized displacements, rotation $\omega_{3}^{h}$, are interpolated by Lagrange quadratic functions denoted $N q_{j}(\xi)$. This choice allows the same order of interpolation for both $w_{0,1}^{h}$ and $\omega_{3}^{h}$ in the corresponding transverse shear strain components due to bending, thus avoiding transverse shear locking according to the field compatibility approach [71].

Finally, traction $u^{h}, v^{h}$ and $u_{31}^{1}$ are interpolated by Lagrange quadratic functions.

\subsubsection{Elementary matrices}

In the previous section, the finite element approximations were defined, and elementary mass $\left[M_{u u}^{e}\right]$ matrix can be deduced from Eq. (13). It has the following expression:

$\left[M_{u u}^{e}\right]=\int_{L_{e}}[N]^{T}[m][N] d L_{e}$

where $[N]$ are deduced expressing the generalized displacement vectors, see Eq. (14), from the elementary vector of degrees of freedom (dof) denoted $\left[q_{e}\right]$ by:

$\left[\mathscr{E}_{u}\right]=[N]\left[q_{e}\right]$

The matrix $[N]$ contains only the interpolation functions.

The same technique can be used defining the elementary mechanical load vector and the elementary rigidity matrix, denoted $\left[B_{u}^{e}\right]$ and $\left[K_{u u}^{e}\right]$ respectively, but it is not detailed here.

\section{Numerical examples: free vibration tests}

Some examples of sandwich and laminated beams are used to evaluate these finite elements. It should be noted that this sinus family has been already evaluated in the static case [70]. It has shown good features for all the standard requirements: it has a proper rank without any spurious energy modes, and it does not imply shear locking.

Here, we focus on the dynamic analyses which are carried out in the free vibration case. It concerns large variety of boundary conditions with wide range of length to thickness ratios for symmetric, unsymmetric and different types of sandwich beams. These examples are taken from $[12,72,73,18,36]$. The results are compared with the ANSYS solution with a very refined mesh, exact 2D solution or theories available from the literature. Some of these
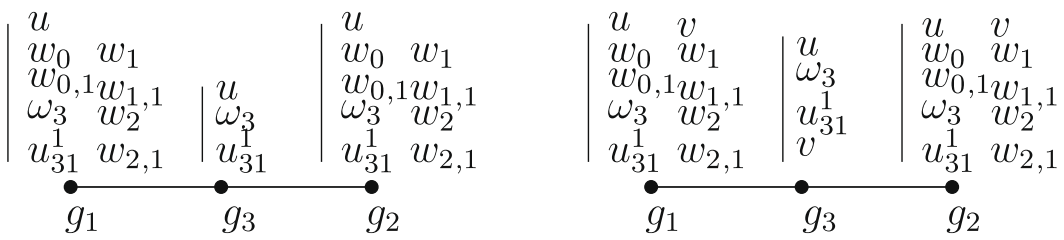

Fig. 3. Description of the laminated beam finite element d.o.f. - SinRef-6p (left) - SinRef-7p (right). 
examples are extended to a very thick beam to assess these finite elements.

\subsection{Convergence study for the SinRef-7p model [73]}

First, a convergence study with respect to the mesh is carried out. A symmetric three layers beam is considered with an aspect ratio $S=10$. It is detailed below:

Geometry: composite cross-ply beam $\left(0^{\circ} / 90^{\circ} / 0^{\circ}\right)$ and length to thickness ratio $S=10$, three layers of equal thickness.

Boundary conditions: simply supported beam. Material properties:

$$
\begin{aligned}
& E_{L}=181 \mathrm{GPa}, \quad E_{T}=10.3 \mathrm{GPa}, \quad G_{L T}=7.17 \mathrm{GPa}, \\
& G_{T T}=2.87 \mathrm{GPa}, \quad v_{L T}=0.25, \quad v_{T T}=0.33
\end{aligned}
$$

where $L$ and $T$ refer to the fiber and transverse direction respectively.

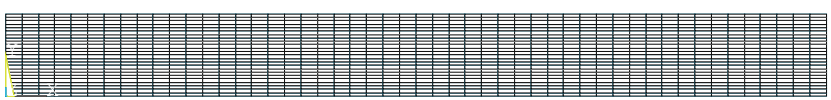

Fig. 4. Mesh with 1275 dofs (ANSYS).

Table 1

Table of principal notation

\begin{tabular}{ll}
\hline$[\sigma]$ & Stress tensor \\
{$[\varepsilon]$} & Strain tensor \\
$C_{i j}$ & Elastic stiffness modulus \\
{$\left[M_{u u}^{e}\right]$} & Elementary mass matrix \\
{$\left[\mathscr{E}_{u}\right],\left[\mathscr{E}_{s}\right]$} & Generalized displacement vector \\
{$[N]$} & Interpolation functions vector \\
{$\left[q_{e}\right]$} & Degrees of freedom elementary vector \\
$\vec{u}$ & Displacement vector \\
$L$ & Length of the beam \\
$b$ & Width of the beam \\
$h, h_{f}, h_{c}$ & Height of the beam, face, and core respectively \\
$N C$ & Number of layers \\
$N$ & Number of elements \\
$t$ & Time \\
$S$ & Length to thickness ratio \\
$\alpha_{k}$ & Continuity coefficients for the Sin-c model \\
$\left(\delta_{i}^{k}, \beta_{i}^{k}\right)_{i=1,2,3}$ & Continuity coefficients for the SinRef-c model \\
Sin & Sinus model without continuity requirements [61] \\
Sin-c & Sinus model with continuity requirements \\
SinRef-c & Refined sinus model with continuity requirements \\
SinRef-6p & Refined sinus model with continuity requirements including \\
SinRef-7p & six unknowns \\
& Refined sinus model with continuity requirements including \\
\hline
\end{tabular}

The same study is carried out with the commercial code ANSYS [74]. A very refined mesh with a $2 \mathrm{D}$ approach is considered as a reference. The mesh of 1275 dofs is shown in Fig. 4.

Table 2 shows the quick convergence, and a $N=8$ mesh seems to be sufficient to model the laminated composite beam for a dynamic analysis. The \% error is very low for the first six frequencies.

\section{2. symmetric laminated composite $[12,72]$}

The example is issued from [12] and [72]. It deals with a symmetric laminated composite with the following characteristics:

Geometry: the beam studied has a length of $L=6.35 \mathrm{~m}$, and a thickness $h=0.2794 \mathrm{~m}$ (thin $S \approx 22.7$ ), and $h=2.794 \mathrm{~m}$ (thick $S \approx 2.2$ ). It possesses three layers at $\left(90^{\circ} / 0^{\circ} / 90^{\circ}\right)$, with thickness $(0.25 h / 0.5 h / 0.25 h)$.

Boundary conditions: simply supported beam.

Material properties: The material used is boron epoxy which has the following mechanical properties:

$E_{11}=241.5 \mathrm{GPa}, \quad E_{22}=E_{33}=18.89 \mathrm{GPa}, \quad G_{12}=G_{13}=5.18 \mathrm{GPa}$
$G_{23}=3.45 \mathrm{GPa}, \quad v_{12}=v_{13}=0.24, \quad v_{23}=0.25, \quad \rho=2015 \mathrm{~kg} / \mathrm{m}^{3}$.

Mesh: $\mathrm{N}=8$.

Results: the mode shapes are precised as: bend, sh, $t / c$, thic for bending, shear, axial traction/compression and thickness mode respectively.The notation of sinus models are given in Table 1.

Tables 3 and 4 present numerical values of frequencies for the thin and very thick beam. These results show the excellent agreement with reference values for eight and seven natural frequencies. Results of the SinRef-c model are better than those of the Sin and Sin-c models, especially for the thick beam. The maximal $\%$ error does not exceed 2.9, whereas the two others have an error of $17 \%$ and $14 \%$ respectively. The SinRef- $7 p$ model seems to be the best model among the sinus family with a maximal \% error equal to 1.6 regardless of the slenderness.

Table 2

Mesh convergence study for the SinRef-7p model - natural frequencies - three-layers $\left(0^{\circ} / 90^{\circ} / 0^{\circ}\right)-S=10$

\begin{tabular}{lccclll}
\hline$N$ & \multicolumn{5}{l}{ Frequencies $(\mathrm{Hz})$} \\
\cline { 2 - 7 } & $2(38$ dofs $)$ & Error (\%) & $4(66$ dofs) & Error (\%) & $8(122$ dofs) & Error $(\%)$ \\
\hline Bend & 38.15 & 0.4 & 38.04 & 0.1 & 38.04 & 0.1 \\
Bend & 115.67 & 4.4 & 110.99 & 0.2 & 110.81 & 0.0 \\
Bend & 211.29 & 11.8 & 190.07 & 0.6 & 188.99 & 0.0 \\
Bend & - & - & 275.97 & 2.5 & 269.12 & 0.0 \\
Bend & 345.01 & 1.8 & 365.80 & 4.1 & 351.50 & 0.0 \\
t/c & 391.33 & 2.6 & 389.96 & 2.3 & 389.86 & 2.2 \\
\hline
\end{tabular}

Table 3

\begin{tabular}{|c|c|c|c|c|c|c|c|c|c|c|c|}
\hline & \multicolumn{11}{|c|}{ Frequencies $(\mathrm{Hz})$ thin beam } \\
\hline & $\operatorname{Sin}$ & Error $(\%)$ & Sin-c & Error (\%) & SinRef-c & Error (\%) & SinRef-6p & Error (\%) & SinRef-7p & Error (\%) & Ansys \\
\hline Bend & 14.97 & 0.2 & 14.98 & 0.3 & 14.97 & 0.2 & 14.97 & 0.2 & 14.96 & 0.2 & 14.93 \\
\hline Bend & 57.85 & 0.3 & 57.94 & 0.4 & 57.80 & 0.2 & 57.83 & 0.3 & 57.69 & 0.0 & 57.67 \\
\hline Bend & 123.55 & 0.5 & 123.96 & 0.8 & 123.33 & 0.3 & 123.45 & 0.4 & 122.90 & 0.0 & 122.90 \\
\hline Bend & 206.18 & 0.8 & 207.23 & 1.3 & 205.65 & 0.5 & 205.95 & 0.7 & 204.59 & 0.0 & 204.50 \\
\hline Bend & 300.71 & 0.9 & 302.75 & 1.8 & 299.77 & 0.8 & 300.39 & 1.1 & 297.90 & 0.2 & 297.23 \\
\hline Bend & 403.60 & 1.5 & 406.91 & 2.4 & 402.29 & 1.2 & 403.35 & 1.5 & 399.56 & 0.6 & 397.28 \\
\hline Bend & 512.67 & 2. & 517.43 & 3. & 511.15 & 1.7 & 512.78 & 2.1 & 507.72 & 1.1 & 502.19 \\
\hline sh & 640.06 & 1.5 & 632.94 & 0.4 & 634.37 & 0.6 & 634.37 & 0.7 & 634.37 & 0.7 & 630.25 \\
\hline
\end{tabular}

Natural frequencies - three-layers $\left(90^{\circ} / 0^{\circ} / 90^{\circ}\right)-S \approx 22.7$. 
Table 4

Natural frequencies - three-layers $\left(90^{\circ} / 0^{\circ} / 90^{\circ}\right)-S \approx 2.2$.

\begin{tabular}{|c|c|c|c|c|c|c|c|c|c|c|c|}
\hline & \multicolumn{11}{|c|}{ Frequencies $(\mathrm{Hz})$ thick beam } \\
\hline & $\operatorname{Sin}$ & Error $(\%)$ & Sin-c & Error (\%) & SinRef-c & Error $(\%)$ & SinRef-6p & Error (\%) & SinRef-7p & Error (\%) & Ansys \\
\hline Bend & 82.81 & 0.7 & 83.66 & 1. & 82.78 & 0.7 & 83.11 & 1.1 & 82.36 & 0.2 & 82.17 \\
\hline Bend & 195.62 & 0.2 & 195.67 & 0.3 & 195.83 & 0.3 & 196.82 & 0.8 & 196.45 & 0.6 & 195.22 \\
\hline sh & 277.98 & 1.3 & 274.94 & 0.2 & 274.31 & 0. & 274.31 & 0.0 & 274.29 & 0.0 & 274.31 \\
\hline Bend & 319.36 & 2.9 & 313.36 & 1. & 311.73 & 0.5 & 312.92 & 0.9 & 312.91 & 0.9 & 310.07 \\
\hline Bend & 460.18 & 8.4 & 442.07 & 4.1 & 428.96 & 1. & 429.48 & 1.2 & 429.43 & 1.2 & 424.311 \\
\hline Bend & 515.41 & 17.4 & 501.47 & 14.2 & 451.63 & 2.9 & 450.69 & 2.7 & 439.22 & 0.1 & 438.81 \\
\hline Bend & 621.47 & 15.6 & 585.51 & 8.9 & 547.42 & 1.8 & 546.29 & 1.7 & 546.14 & 1.6 & 537.42 \\
\hline
\end{tabular}

It should be noted that the values of the natural frequencies are always overestimated when compared to ANSYS finite element solution.

\subsection{Free vibration of symmetric and anti-symmetric lay-up [73]}

In this section, two stacking sequences of laminated composite are considered.

Geometry: composite cross-ply beam $\left(0^{\circ} / 90^{\circ} / 0^{\circ}\right),\left(0^{\circ} / 90^{\circ}\right)$ and length to thickness ratio $S=2, S=5, S=10, S=20$.

Boundary conditions: free vibration of a simply supported beam. Material properties: same material properties as in Section 3.1. Results: the results are presented under a non-dimensional natural frequency as follows: $\bar{\omega}=\omega L S\left(\rho / Y_{0}\right)^{1 / 2}$, with $Y_{0}=$ $10.3 \mathrm{GPa}, \rho=1578 \mathrm{~kg} / \mathrm{m}^{3}$.

They are compared with exact two-dimensional elasticity solution from [73] and results computed from ANSYS.
The shape modes for the thick symmetric and anti-symmetric beams are illustrated in Figs. 5 and 6.

It can be noticed that the natural frequencies given in Table 5 by the refined models for the symmetric lay-up are in excellent agreement with the reference solution for $S \geqslant 5$. The errors are less than $2 \%$, excepted for thickness mode frequencies. The SinRef-c model improves results computed from the Sin and Sin-c models regardless of the length to thickness ratio. However, it is also observed that the two later models provide satisfactory results for moderately thick cases.

The effect of the transverse normal stress is significant for the very thick beam. On the one hand, the SinRef-6p and SinRef-7p models give accurate results for $S=2$ compared with the SinRefc model. On the other hand, they allow to exhibit thickness-stretch modes even if the corresponding error seems high. In fact, Fig. 5 shows that the fifth mode shape is symmetrical.

As far as the anti-symmetric lay-up $\left(0^{\circ} / 90^{\circ}\right)$ is concerned, the errors given in Table 6 vary from $0 . \%$ to $1.8 \%$ for the SinRef- $7 p$
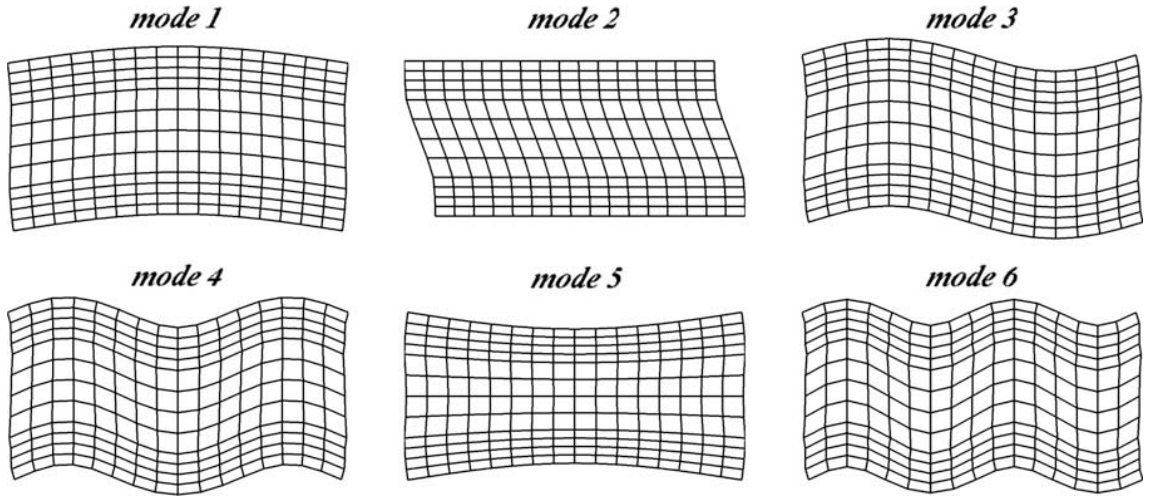

Fig. 5. Shape modes for the symmetric beam $\left(0^{\circ} / 90^{\circ} / 0^{\circ}\right)-S=2-\operatorname{SinRef}-7 \mathrm{p}$.

mode 1

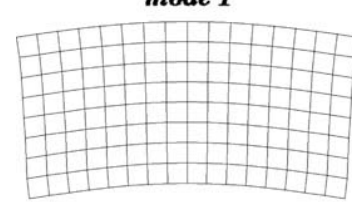

mode 4

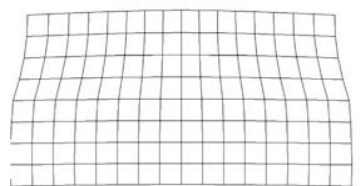

mode 2

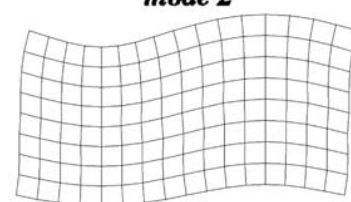

mode 5

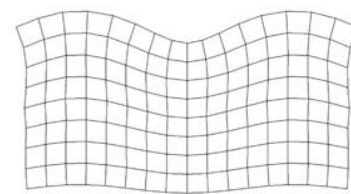

mode 3

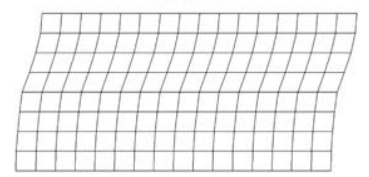

mode 6

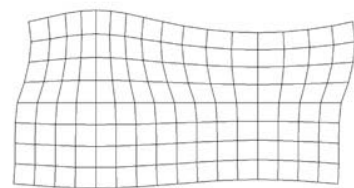

Fig. 6. Shape modes for the unsymmetric beam $\left(0^{\circ} / 90^{\circ}\right)-S=2-\operatorname{SinRef}-7 \mathrm{p}$. 
Table 5

Natural frequencies $-\left(0^{\circ} / 90^{\circ} / 0^{\circ}\right)$

\begin{tabular}{|c|c|c|c|c|c|c|c|c|c|c|c|c|c|}
\hline \multirow[t]{2}{*}{$S$} & \multicolumn{13}{|c|}{ Natural frequencies $\bar{\omega}$} \\
\hline & & $\operatorname{Sin}$ & Error $(\%)$ & Sin-c & Error (\%) & SinRef-c & Error $(\%)$ & SinRef-6p & Error $(\%)$ & SinRef-7p & Error (\%) & Ansys & Exact 2D [73] \\
\hline \multirow[t]{7}{*}{2} & Bend & 3.50 & 1.6 & 3.55 & 3.4 & 3.53 & 2.4 & 3.45 & 0.2 & 3.45 & 0.1 & 3.45 & - \\
\hline & sh & 7.48 & 6.7 & 7.03 & 0.3 & 11.08 & 58.1 & 7.01 & 0.0 & 7.01 & 0.0 & 7.01 & - \\
\hline & Bend & 8.17 & 6.3 & 9.10 & 18 & 8.16 & 6.2 & 7.70 & 0.2 & 7.69 & 0.1 & 7.68 & - \\
\hline & Bend & 14.31 & 19.2 & 17.11 & 42 & 13.02 & 8.5 & 12.08 & 0.7 & 12.08 & 0.6 & 12.00 & - \\
\hline & Thic & - & - & - & - & - & - & 14.59 & 0.0 & 14.59 & 0.0 & 14.59 & - \\
\hline & Bend & 22.19 & 37 & 27.62 & 70 & 18.03 & 11.3 & 16.48 & 1.7 & 16.45 & 1.6 & 16.20 & - \\
\hline & Thic & - & - & - & - & - & - & 17.22 & 9.1 & 17.22 & 9 & 18.94 & - \\
\hline \multirow[t]{8}{*}{5} & Bend & 6.94 & 1.9 & 6.82 & 0.2 & 6.81 & 0.2 & 6.82 & 0.3 & 6.81 & 0.1 & 6.81 & 6.806 \\
\hline & Bend & 16.80 & 1.6 & 16.79 & 1.6 & 16.54 & 0.1 & 16.56 & 0.2 & 16.53 & 0.0 & 16.52 & 16.515 \\
\hline & Bend & 27.17 & 1.6 & 28.07 & 5. & 26.73 & 0.04 & 26.75 & 0.1 & 26.72 & 0.0 & 26.72 & 26.688 \\
\hline & Bend & 38.51 & 3.1 & 41.35 & 10.7 & 37.32 & 0.02 & 37.34 & 0.0 & 37.31 & 0.0 & 37.33 & 37.255 \\
\hline & Thic & - & - & - & - & - & - & 47.87 & 9.4 & 47.87 & 9.4 & 43.75 & - \\
\hline & $\mathrm{sh}$ & 46.76 & 6.7 & 43.93 & 0.3 & 43.80 & 0.01 & 43.80 & 0.0 & 43.79 & 0.0 & 43.80 & - \\
\hline & Bend & 47.86 & 0.6 & 47.86 & 0.6 & 48.18 & 0.4 & 48.21 & 0.1 & 48.18 & 0.0 & 48.18 & 48.035 \\
\hline & Bend & 51.24 & 13.3 & 57.13 & 3.3 & 59.26 & 0.2 & 59.25 & 0.2 & 59.22 & 0.2 & 59.11 & 58.876 \\
\hline \multirow[t]{7}{*}{10} & Bend & 9.44 & 1. & 9.34 & 0. & 9.36 & 0.1 & 9.36 & 0.2 & 9.36 & 0.1 & 9.34 & 9.343 \\
\hline & Bend & 27.76 & 1.9 & 27.29 & 0.1 & 27.25 & 0.1 & 27.30 & 0.2 & 27.25 & 0.0 & 27.24 & 27.224 \\
\hline & Bend & 47.36 & 1.9 & 46.78 & 0.6 & 46.53 & 0.1 & 46.56 & 0.2 & 46.48 & 0.0 & 46.47 & 46.416 \\
\hline & Bend & 67.29 & 1.6 & 67.23 & 1.6 & 66.25 & 0.1 & 66.30 & 0.2 & 66.19 & 0.0 & 66.19 & 66.058 \\
\hline & Bend & 87.77 & 1.5 & 89.13 & 3.1 & 86.51 & 0.1 & 86.57 & 0.2 & 86.45 & 0.0 & 86.43 & 86.169 \\
\hline & $\mathrm{t} / \mathrm{c}$ & 95.73 & 2. & 95.73 & 2. & 95.90 & 2.2 & 95.88 & 2.2 & 95.88 & 2.2 & 93.78 & - \\
\hline & Bend & - & & 113.04 & 5.4 & 107.38 & 0.1 & 107.45 & 0.2 & 107.33 & 0.1 & 107.20 & 106.75 \\
\hline \multirow[t]{7}{*}{20} & Bend & 10.67 & 0.2 & 10.64 & 0. & 10.65 & 0.1 & 10.66 & 0.2 & 10.65 & 0.1 & 10.64 & 10.64 \\
\hline & Bend & 37.78 & 1. & 37.39 & 0. & 37.45 & 0.1 & 37.46 & 0.2 & 37.43 & 0.1 & 37.40 & 37.374 \\
\hline & Bend & 72.98 & 1.5 & 71.87 & 0. & 71.94 & 0.1 & 71.97 & 0.2 & 71.87 & 0.0 & 71.85 & 71.744 \\
\hline & Bend & 111.23 & 1.9 & 109.35 & 0.1 & 109.30 & 0.1 & 109.37 & 0.2 & 109.18 & 0.0 & 109.15 & 108.89 \\
\hline & Bend & 150.57 & 2. & 148.21 & 0.4 & 147.83 & 0.2 & 147.94 & 0.3 & 147.67 & 0.1 & 147.54 & 147.04 \\
\hline & Bend & 190.54 & 2.1 & 188.26 & 0.9 & 187.19 & 0.3 & 187.31 & 0.4 & 186.97 & 0.2 & 186.53 & 185.68 \\
\hline & $\mathrm{t} / \mathrm{c}$ & 191.47 & 0.4 & 191.47 & 0.4 & 191.81 & 0.6 & 191.81 & 0.7 & 191.81 & 0.7 & 190.52 & - \\
\hline
\end{tabular}

Table 6

Natural frequencies - anti-symmetric lay-up $\left(0^{\circ} / 90^{\circ}\right)$.

\begin{tabular}{|c|c|c|c|c|c|c|c|c|c|c|c|c|}
\hline \multirow[t]{2}{*}{$S$} & \multicolumn{12}{|c|}{ Natural frequencies $\bar{\omega}$} \\
\hline & & Sin & Error (\%) & Sin-c & Error (\%) & SinRef-c & Error (\%) & SinRef-6p & Error (\%) & SinRef-7p & Error (\%) & Ansys \\
\hline \multirow[t]{7}{*}{2} & Bend & 3.50 & 9 & 3.55 & 11 & 3.24 & 1.2 & 3.25 & 1.6 & 3.22 & 0.7 & 3.20 \\
\hline & Bend & 7.48 & 1.5 & 9.10 & 23 & 7.87 & 6.8 & 7.67 & 4.0 & 7.58 & 2.9 & 7.37 \\
\hline & sh & 14.31 & 84 & 7.03 & 9 & 7.76 & 0.0 & 7.76 & 0.0 & 7.76 & 0.0 & 7.76 \\
\hline & Bend & 19.18 & 116 & 19.18 & 116 & 8.94 & 1.1 & 8.90 & 0.6 & 8.89 & 0.5 & 8.85 \\
\hline & Bend & 25.16 & 129 & 27.62 & 152 & 12.87 & 17.7 & 11.63 & 6.3 & 11.50 & 5.1 & 10.94 \\
\hline & Thic & - & - & - & - & - & - & 14.46 & 13.6 & 14.33 & 12.6 & 12.73 \\
\hline & Thic & - & - & - & - & - & - & 14.00 & 2.2 & 13.97 & 1.9 & 13.71 \\
\hline \multirow[t]{6}{*}{5} & Bend & 4.83 & 1 & 4.87 & 2 & 4.78 & 0.2 & 4.80 & 0.4 & 4.78 & 0.2 & 4.77 \\
\hline & Bend & 15.19 & 4 & 15.60 & 6 & 14.71 & 0.6 & 14.78 & 1.1 & 14.67 & 0.4 & 14.61 \\
\hline & Bend & 27.30 & 7 & 28.64 & 12 & 25.87 & 1.8 & 25.90 & 1.9 & 25.65 & 0.9 & 25.40 \\
\hline & tc & 38.12 & 7 & 36.39 & 3 & 35.56 & 0.4 & 35.52 & 0.3 & 35.45 & 0.1 & 35.42 \\
\hline & Bend & 40.29 & 12 & 43.09 & 19 & 37.42 & 4 & 37.09 & 3.0 & 36.68 & 1.8 & 36.02 \\
\hline & sh & 54.15 & 11 & 50.29 & 3 & 48.52 & 0. & 48.53 & 0.0 & 48.51 & 0.0 & 48.52 \\
\hline \multirow[t]{6}{*}{10} & Bend & 5.30 & 0.3 & 5.32 & 0.5 & 5.29 & 0.1 & 5.30 & 0.2 & 5.30 & 0.1 & 5.29 \\
\hline & Bend & 19.33 & 1 & 19.49 & 2 & 19.14 & 0.1 & 19.20 & 0.4 & 19.14 & 0.1 & 19.12 \\
\hline & Bend & 38.67 & 2 & 39.33 & 4 & 37.87 & 0.2 & 38.03 & 0.7 & 37.83 & 0.1 & 37.77 \\
\hline & Bend & 60.91 & 4 & 62.57 & 7 & 58.97 & 0.6 & 59.24 & 1.1 & 58.81 & 0.4 & 58.60 \\
\hline & Bend & 84.87 & 6 & 88.13 & 9 & 81.26 & 1 & 81.53 & 1.6 & 80.81 & 0.7 & 80.22 \\
\hline & tc & 90.06 & 2 & 88.92 & 0.5 & 88.65 & 0.2 & 88.63 & 0.2 & 88.55 & 0.1 & 88.44 \\
\hline \multirow[t]{7}{*}{20} & Bend & 5.45 & $<0.1$ & 5.46 & 0.1 & 5.45 & 0.1 & 5.46 & 0.1 & 5.46 & 0.1 & 5.45 \\
\hline & Bend & 21.23 & 0.3 & 21.28 & 0.4 & 21.20 & 0.1 & 21.22 & 0.2 & 21.20 & 0.1 & 21.18 \\
\hline & Bend & 45.86 & 0.7 & 46.08 & 1 & 45.62 & 0.1 & 45.71 & 0.3 & 45.63 & 0.2 & 45.55 \\
\hline & Bend & 77.58 & 1 & 78.23 & 2 & 76.81 & 0.3 & 77.03 & 0.6 & 76.80 & 0.3 & 76.59 \\
\hline & Bend & 114.86 & 2 & 116.31 & 3 & 113.11 & 0.6 & 113.52 & 1.0 & 113.05 & 0.6 & 112.40 \\
\hline & Bend & 156.58 & 3 & 159.32 & 5 & 153.29 & 1 & 153.95 & 1.6 & 153.13 & 1.1 & 151.48 \\
\hline & $\mathrm{tc}$ & 188.63 & 0.4 & 188.09 & 0.1 & 188.26 & 0.2 & 188.25 & 0.2 & 188.20 & 0.2 & 187.89 \\
\hline
\end{tabular}

model. The improvement is really significant compared with the four other models, especially for the very thick beam where the Sin and Sin-c models give very poor results. Nevertheless, the
SinRef-7p results are very close to the SinRef-6p frequencies. Again, only two models have the capability to represent thickness mode shape (cf. Fig. 6) as they assume quadratic variation of 
transverse displacement through the thickness. The fifth and sixth modes clearly illustrate the effect of transverse normal deformation. It can be noticed that these modes are not symmetrical.

\subsection{Free vibration of sandwich beam}

\subsubsection{Three-layer sandwich beam [73]}

The first example of sandwich beam has the following characteristics:

Geometry: the three-layer sandwich beam has graphite-epoxy faces and a soft core with thickness $0.1 \mathrm{~h} / 0.8 \mathrm{~h} / 0.1 \mathrm{~h}$ and length to thickness ratio $S=2, S=5, S=10, S=20$.

Boundary conditions: simply supported beam.

Material properties: Face: $E_{11}=131.1 \mathrm{GPa}, E_{22}=E_{33}=6.9 \mathrm{GPa}$ $G_{12}=3.588 \mathrm{GPa}, G_{13}=3.088 \mathrm{GPa}, G_{23}=2.3322 \mathrm{GPa}, v_{12}=v_{13}=$ $0.32, v_{23}=0.49, \rho_{f}=1000 \mathrm{~kg} / \mathrm{m}^{3}$. Core $: E_{11}=0.2208 \mathrm{MPa}$, $E_{22}=0.2001 \mathrm{MPa}, \quad E_{33}=2760 \mathrm{MPaG}_{12}=16.56 \mathrm{MPa}, \quad G_{13}=$ $545.1 \mathrm{MPa}, G_{23}=455.4 \mathrm{MPa}, v_{12}=0.99, v_{13}=0.00003, v_{23}=$ $0.00003, \rho_{c}=70 \mathrm{~kg} / \mathrm{m}^{3}$.

Results: results are presented under a non-dimensional natural frequency as follows:

$\bar{\omega}=\omega L S\left(\rho_{f} / Y_{0}\right)^{1 / 2}$ with $Y_{0}=6.9 \mathrm{GPa}-C f$. Table 7
As far as the sandwich beam with $S \geqslant 5$ is concerned, Table 7 shows that the refined sinus models yield accurate results in all cases. The magnitude of the relative error never exceed $3.6 \%$ and $5.8 \%$ for the three refined sinus and sinus models respectively.

Then, the five models are able to estimate accurately the natural frequencies of a sandwich beam. In our case, the SinRef-7p model gives the best results. For example, the \% error is less than 0.2 for $S=5$, and is equal to $4 \%$ for the thickness mode. We can also put the emphasis on the effect of the relation between $w_{0}\left(x_{1}\right)_{1}$ and $v\left(x_{1}\right)$ for the SinRef-7p and SinRef-6p models. The accuracy on frequencies is improved with one more unknown.

For $S=2$, remarks of Section 3.3 are identical. It should be noted that the Sin and Sin-c models allow to estimate correctly the first three frequencies. Nevertheless, the estimation of frequencies is improved owing to the transverse normal effect in the SinRef-6p and SinRef-7p models.

Fig. 7 illustrates three thickness mode shapes occurring in this very thick case. Moreover, these models are shown to provide better accuracy than the zig-zag model described in [73]. In this reference, we also notice the difficulty to estimate the frequencies of thickness modes.

Finally, it can be observed that the use of more unknown functions in the formulation seems to make the beam more flexible.
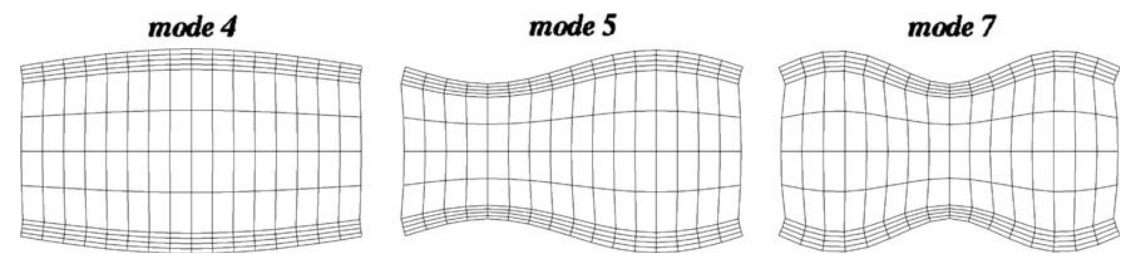

Fig. 7. Thickness mode shape for the sandwich beam $-S=2-$ SinRef-7p.

Table 7

Natural frequencies - sandwich beam.

\begin{tabular}{|c|c|c|c|c|c|c|c|c|c|c|c|c|c|}
\hline \multirow[t]{2}{*}{$S$} & \multicolumn{13}{|c|}{ Natural frequencies $\bar{\omega}$} \\
\hline & & Sin & Error (\%) & Sin-c & Error (\%) & SinRef-c & Error (\%) & SinRef-6p & Error (\%) & SinRef-7p & Error (\%) & Ansys & Exact 2D [73] \\
\hline \multirow[t]{8}{*}{2} & Bend & 3.67 & 4 & 3.57 & 1.3 & 3.65 & 3.5 & 3.64 & 3 & 3.53 & 0.2 & 3.53 & - \\
\hline & sh & 5.54 & 3.7 & 5.34 & 0.0 & 5.48 & 2.5 & 5.48 & 2.5 & 5.34 & 0.1 & 5.34 & - \\
\hline & Bend & 7.99 & 5.4 & 8.03 & 5.9 & 7.88 & 3.8 & 7.74 & 2 & 7.60 & 0.2 & 7.58 & - \\
\hline & Thic & - & - & - & & - & - & 11.07 & 4 & 11.07 & 4 & 11.61 & - \\
\hline & Thic & - & - & - & & - & - & 9.40 & 19 & 9.40 & 19 & 11.66 & - \\
\hline & Bend & 13.22 & 10 & 13.77 & 14 & 12.46 & 3.9 & 12.08 & 0.7 & 11.97 & 0.2 & 11.99 & - \\
\hline & Thic & - & - & - & - & - & - & 15.00 & 24 & 15.00 & 24 & 12.09 & - \\
\hline & Bend & 19.61 & 18 & 21.08 & 27 & 17.22 & 4.1 & 16.49 & 0.3 & 16.45 & 0.5 & 16.53 & - \\
\hline \multirow[t]{7}{*}{5} & Bend & 8.09 & 3.4 & 7.85 & 0.3 & 8.04 & 2.7 & 8.05 & 2.9 & 7.83 & 0.1 & 7.82 & 7.82 \\
\hline & Bend & 17.96 & 3.9 & 17.43 & 0.8 & 17.86 & 3.3 & 17.83 & 3.2 & 17.31 & 0.1 & 17.28 & 17.27 \\
\hline & Bend & 28.01 & 4. & 27.42 & 1.8 & 27.88 & 3.5 & 27.71 & 2.9 & 26.97 & 0.2 & 26.93 & 26.90 \\
\hline & sh & 34.66 & 3.7 & 33.42 & 0. & 34.22 & 2.4 & 34.22 & 2.5 & 33.37 & 0.1 & 33.40 & - \\
\hline & Bend & 38.62 & 4.3 & 38.27 & 3.4 & 38.35 & 3.6 & 37.91 & 2.4 & 37.06 & 0.1 & 37.01 & 36.93 \\
\hline & Bend & 50.06 & 5.2 & 50.32 & 5.8 & 49.31 & 3.6 & 48.46 & 1.9 & 47.58 & 0.1 & 47.55 & 47.39 \\
\hline & Thic & - & - & - & - & - & - & 55.39 & 4 & 55.39 & 4 & 58.02 & - \\
\hline \multirow[t]{7}{*}{10} & Bend & 12.49 & 2.1 & 12.25 & 0.1 & 12.45 & 1.7 & 12.47 & 1.9 & 12.26 & 0.1 & 12.23 & 12.23 \\
\hline & Bend & 32.37 & 3.4 & 31.41 & 0.3 & 32.16 & 2.7 & 32.21 & 2.9 & 31.33 & 0.1 & 31.30 & 31.29 \\
\hline & Bend & 52.17 & 3.8 & 50.53 & 0.5 & 51.82 & 3.1 & 51.84 & 3.1 & 50.31 & 0.1 & 50.26 & 50.21 \\
\hline & Bend & 71.90 & 3.8 & 69.77 & 0.8 & 71.48 & 3.2 & 71.37 & 3.1 & 69.26 & 0.1 & 69.21 & 68.09 \\
\hline & Bend & 91.88 & 3.9 & 89.52 & 1.2 & 91.43 & 3.4 & 91.08 & 3.0 & 88.51 & 0.1 & 88.41 & 88.18 \\
\hline & Bend & 112.43 & 4. & 110.11 & 1.9 & 111.91 & 3.5 & 111.20 & 2.9 & 108.25 & 0.2 & 108.02 & 107.61 \\
\hline & $t / c$ & 121.04 & 0.8 & 121.04 & 0.8 & 121.36 & 1.1 & 121.11 & 0.9 & 121.11 & 0.9 & 120.03 & - \\
\hline \multirow[t]{6}{*}{20} & Bend & 15.50 & 0.8 & 15.39 & 0. & 15.51 & 0.8 & 15.52 & 0.9 & 15.41 & 0.2 & 15.38 & 15.38 \\
\hline & Bend & 49.99 & 2. & 49.04 & 0.1 & 49.82 & 1.7 & 49.88 & 1.8 & 49.04 & 0.1 & 48.98 & 48.94 \\
\hline & Bend & 89.53 & 2.8 & 87.18 & 0.2 & 89.03 & 2.3 & 89.16 & 2.5 & 87.07 & 0.1 & 87.01 & 86.90 \\
\hline & Bend & 169.56 & 3.6 & 164.26 & 0.4 & 168.41 & 2.9 & 168.55 & 3.0 & 163.69 & 0.1 & 163.58 & 163.12 \\
\hline & Bend & 209.45 & 3.8 & 202.88 & 0.6 & 208.08 & 3.1 & 208.10 & 3.2 & 201.94 & 0.1 & 201.64 & 200.87 \\
\hline & $\mathrm{t} / \mathrm{c}$ & 242.08 & 0.2 & 242.06 & 0.2 & 242.73 & 0.4 & 242.64 & 0.4 & 240.59 & 0.4 & 241.61 & - \\
\hline
\end{tabular}


3.4.2. Five-layer sandwich beam [18]

In this part, a five-layer sandwich beam is concerned. It is described in the following.

Geometry: the five-layer sandwich beam with three stiff isotropic layers at top/bottom/middle and two soft cores sandwiched in between (face/core/face/core/face): $h_{c}=10.16 \mathrm{~mm}, h_{f}=$ $0.508 \mathrm{~mm}-L=508 \mathrm{~mm}$, width $=25.4 \mathrm{~mm}, h=21.844 \mathrm{~mm}-$ $S \approx 2.5,5,25$

Boundary conditions: simply supported beam.

Material properties: isotropic face: $E_{f}=68.97 \times 10^{3} \mathrm{MPa}$, $v=0.3 \rho=2.7155 \times 10^{2} \mathrm{~kg} / \mathrm{m}^{3} ;$ isotropic core: $G_{c}=34.485$ MPa, $v=0.3, \rho=67.8840 \mathrm{~kg} / \mathrm{m}^{3}$.

The natural frequencies obtained from the present investigation are compared in Table 8 with two reference solutions (from [18] and the commercial code). Again, the SinRef-7p model yields very accurate results even for a very thick case. The main improvement occurs between the SinRef- $6 p$ and SinRef-7p models what shows the importance of the additional unknown $v\left(x_{1}\right)$. For this example, we also observe the necessity to satisfy the continuity of the transverse shear stress at the layer interfaces. This effect is particularly high (Cf Sin and Sin-c results).

\subsection{Influence of boundary conditions}

Free vibrations of beams with arbitrary boundary conditions are studied. Under the considerations of Sections 3.2, 3.3 and 3.4, only the SinRef-7p model is applied for the determination of frequencies, namely the most accurate theory among the ones already tested. These results are compared with higher-order shear deformation theory from [11]. It should be noted that these theories do not ensure the continuity of the transverse shear stress on the interfaces between the layers for the unsymmetric beam. This limitation does not exist in our approach.

The considered test has the following characteristics:

Geometry: composite cross-ply beam $\left(0^{\circ} / 90^{\circ} / 0^{\circ}\right)$ and $\left(0^{\circ} / 90^{\circ}\right)$ with $S=5$, and layers of equal thickness.

Boundary conditions: clamped/clamped (CC), free/free (FF), simply supported/free (SF), clamped/simply supported (CS), simply supported/simply supported (SS), clamped/free (CF) beam. Material properties:

$$
\begin{aligned}
& E_{1} / E_{2}=40, \quad G_{12}=G_{13}=0.6 E_{2}, \quad G_{23}=0.5 E_{2}, \\
& v_{12}=0.25
\end{aligned}
$$

Results: the natural frequencies are normalized as $\bar{\omega}=$ $\omega L^{2} \sqrt{\left(\rho / E_{2}\right)} / h$. A comparison with the published numerical results from [11] is carried out. It implies two models:

HSDBT Hyperbolic shear deformation beam theory

PSDBT Parabolic shear deformation beam theory

the indices $d s$ or $c s$ stand for discontinuity and continuity interlaminar stress respectively.

The results for different stacking sequences are given in Table 9 . As one can observe for the symmetric beam, the frequencies for the SinRef-7p model are always upper than these of the two other models, excepted for the CC condition. Concerning the unsymmetric case, results are always lower than the two other discontinuous models, and the difference is about $10 \%$. This fact is already observed by [11] between continuous and discontinuous models. Nevertheless, as for Section 3.3, we can say that the present model exhibits the most reliable performance.

Table 8

\begin{tabular}{|c|c|c|c|c|c|c|c|c|c|c|c|c|}
\hline \multirow[t]{2}{*}{$S$} & \multicolumn{12}{|c|}{ Frequencies $(\mathrm{Hz})$} \\
\hline & Sin & Error (\%) & Sin-c & Error (\%) & SinRef-c & Error (\%) & SinRef-6p & Error (\%) & SinRef-7p & Error (\%) & ANSYS & Ref. [18] \\
\hline \multirow[t]{4}{*}{$\approx 2.5$} & 931.13 & 344 & 203.25 & 2.9 & 225.17 & 7.6 & 226.03 & 8.0 & 203.55 & 2.8 & 209.31 & - \\
\hline & 2366.8 & 451 & 417.42 & 2.7 & 468.20 & 9.1 & 468.20 & 9.1 & 419.67 & 2.2 & 429.12 & - \\
\hline & 2519.5 & 442 & 482.77 & 4 & 469.70 & 1.2 & 475.62 & 2.5 & 463.90 & 0.0 & 464.01 & - \\
\hline & 2769.3 & 318 & 645.38 & 2.5 & 739.50 & 11.7 & 757.36 & 14.4 & 652.69 & 1.4 & 661.86 & - \\
\hline \multirow[t]{7}{*}{$\approx 5$} & 297.24 & 200 & 97.91 & 1.5 & 107.32 & 7.9 & 107.47 & 8.1 & 97.96 & 1.5 & 99.45 & - \\
\hline & 931.32 & 350 & 203.25 & 1.6 & 225.17 & 9.0 & 226.04 & 9.4 & 203.55 & 1.5 & 206.67 & - \\
\hline & 1259.8 & 300 & 309.13 & 1.6 & 345.07 & 9.8 & 347.72 & 10.7 & 310.13 & 1.3 & 314.16 & - \\
\hline & 1647.8 & 288 & 417.43 & 1.5 & 468.20 & 10.5 & 468.20 & 10.5 & 419.86 & 0.9 & 423.80 & - \\
\hline & 2366.9 & 410 & 482.77 & 4 & 470.01 & 1.3 & 475.95 & 2.6 & 463.86 & 0.0 & 464.01 & - \\
\hline & 2519.6 & 369 & 529.24 & 1.4 & 602.06 & 12.2 & 613.15 & 14.2 & 534.28 & 0.4 & 536.69 & - \\
\hline & 2769.3 & 323 & 645.49 & 1.3 & 743.36 & 13.7 & 761.76 & 16.5 & 655.11 & 0.2 & 653.79 & - \\
\hline \multirow[t]{6}{*}{$\approx 25$} & 13.43 & 23 & 11.26 & 3 & 11.58 & 6 & 11.59 & 6 & 11.26 & 3.2 & 10.90 & 10.91 \\
\hline & 52.80 & 65 & 32.58 & 1.7 & 34.64 & 7 & 34.66 & 7 & 32.59 & 1.2 & 32.02 & 32.20 \\
\hline & 115.59 & 113 & 54.74 & 1 & 59.21 & 8 & 59.25 & 8 & 54.77 & 0.2 & 54.23 & 54.65 \\
\hline & 198.34 & 160 & 76.50 & 0.5 & 83.50 & 8 & 83.59 & 8 & 76.58 & 0.2 & 76.09 & 76.74 \\
\hline & 251.95 & 158 & 97.92 & 0.3 & 107.49 & 9 & 107.65 & 9 & 98.10 & 0.4 & 97.61 & 98.47 \\
\hline & 297.39 & 150 & 119.13 & 0.1 & 131.37 & 9 & 131.63 & 9 & 119.52 & 0.4 & 118.94 & 119.96 \\
\hline
\end{tabular}

Frequencies - five-layer sandwich beam [18].

Table 9

\begin{tabular}{|c|c|c|c|c|c|c|c|}
\hline & Models & $\mathrm{FF}$ & $\mathrm{CC}$ & SF & CS & SS & $\mathrm{CF}$ \\
\hline \multirow[t]{3}{*}{$\left(0^{\circ} / 90^{\circ} / 0^{\circ}\right)$} & $\operatorname{PSDBT}_{C s}[11]$ & 18.976 & 11.446 & 13.206 & 10.032 & 8.968 & 4.158 \\
\hline & $\mathrm{HSDBT}_{c s}[11]$ & 18.955 & 11.427 & 13.195 & 10.021 & 8.964 & 4.157 \\
\hline & SinRef-7p & 19.123 & 11.100 & 13.472 & 10.000 & 9.201 & 4.189 \\
\hline \multirow[t]{3}{*}{$\left(0^{\circ} / 90^{\circ}\right)$} & $\operatorname{PSDBT}_{d s}[11]$ & 13.000 & 10.103 & 9.221 & 8.068 & 6.144 & 2.384 \\
\hline & $\operatorname{HSDBT}_{d s}[11]$ & 12.849 & 10.059 & 9.162 & 8.037 & 6.124 & 2.383 \\
\hline & SinRef-7p & 11.709 & 8.743 & 8.413 & 7.153 & 5.671 & 2.289 \\
\hline
\end{tabular}

Comparison of frequencies for composite beams with $\left(0^{\circ} / 90^{\circ} / 0^{\circ}\right)$ and $\left(0^{\circ} / 90^{\circ}\right)$ layouts. 
Table 10

Comparison of non-dimensional frequencies for soft core sandwich beam $\left(0^{\circ} / 90^{\circ}\right)$ core $/ 0^{\circ} / 90^{\circ}$ ).

\begin{tabular}{lllrrrr}
\hline$S$ & Models & $\bar{\omega}$ & & & & \\
\hline 4 & GLHT & 0.638 & 1.800 & 3.631 & 6.133 & 9.276 \\
& ZZT & 0.616 & 1.772 & 3.621 & 6.186 & 9.464 \\
& HSDT-33 & 1.495 & 3.277 & 5.497 & 7.735 & 10.182 \\
& HSDT-Reddy & 2.249 & 4.682 & 7.293 & 10.176 & 13.396 \\
& SinRef-7p & 0.645 & 1.819 & 3.674 & 6.223 & 9.463 \\
10 & GLHT & 1.346 & 2.993 & 5.126 & 7.860 & 11.250 \\
& ZZT & 1.282 & 2.874 & 4.970 & 7.685 & 11.075 \\
& HSDT-33 & 3.468 & 7.355 & 11.402 & 15.748 & 20.481 \\
& HSDT-Reddy & 5.012 & 11.075 & 17.051 & 23.089 & 29.263 \\
& SinRef-7p & 1.361 & 3.026 & 5.183 & 7.961 & 11.442 \\
\hline
\end{tabular}

In all cases, the highest frequencies occur for the FF boundary condition

\subsection{Comparison with results available in the literature}

In this paragraph, the most enriched model (SinRef-7p) is compared with results available in the literature. Unsymmetric beams are chosen from [20].

The finite element is tested with a deep laminated sandwich beam composed of two face sheets of (0/90) lay-up at the top and bottom with core sandwiched in between $\left(0^{\circ} / 90^{\circ} /\right.$ core $\left./ 0^{\circ} / 90^{\circ}\right)$.

Geometry: five-layer sandwich beam with soft core: $h_{c} / h_{f}=10$.

Boundary conditions: simply supported beam.

Material properties:

Face sheets: $E_{1 f}=131 \mathrm{GPa}, E_{2 f}=E_{3 f}=10.34 \mathrm{GPa}, \quad v_{12}=$ $v_{13}=0.22, \quad v_{23}=0.49, G_{12 f}=G_{23 f}=6.895 \mathrm{GPa}, \quad G_{13 f}=$ $6.205 \mathrm{GPa}, \rho_{f}=1627 \mathrm{~kg} / \mathrm{m}^{3}$.

Isotropic core: $G_{c}=3.45 \mathrm{MPa}, v=0 ., E_{c}=6.89 \mathrm{MPa}$, $\rho_{c}=97 \mathrm{~kg} / \mathrm{m}^{3}$.

Results: the natural frequencies are normalized as $\bar{\omega}=$ $\omega L^{2} \sqrt{\left(\rho_{f} / E_{2 f}\right)} / h$. The results of four other models are given from [20]:

- GLHT (6 parameters) analytical results based on global-local higher order theory [59].

- ZZT (3 parameters) zig-zag theory satisfying the continuity of transverse shear stress at interfaces [40].

- HSDT-33 third order theory for in-plane and transverse displacements.

- HSDT-Reddy (3 parameters) Reddy's model.

The comparison of non-dimensional frequencies with the available results from [20] are given in Table 10 for thick and semi-thick beams. In all cases, we observe that the SinRef- $7 p$ models give results very close to the GLHT model which is considered as a reference in [20]. We can also notice that the increasing of the order expansion of the transverse displacement is not sufficient to get good results. In fact, the frequencies of the HSDT-33 model are very overestimated. It is more important to ensure the continuity of the transverse shear stress.

\section{Conclusion}

In the framework of a sinus family, two numerical models have been presented and assessed through a wide variety of stacking sequences, length to thickness ratios, and boundary conditions in free vibration analysis. Special attention is pointed towards the transverse normal stress effect which plays an important role in thick cases. It is a three-node multilayered beam finite element with a parabolic distribution of transverse displacement. Based on sinus equivalent single layer model, a third order kinematic per layer is added, improving the shear bending description for thick beams. There is no need for transverse shear correction factors and all the interface and boundary conditions are exactly satisfied. So, this approach has a strong physical meaning. Finally, the number of unknowns is independent of the number of layers.

All these different examples prove the efficiency of the family of refined sinus models for laminated composite and sandwich beams in the field of finite element. Few elements are needed to obtain good results. The new models have very good capability for a wide area of applications. In particular, for the very thick case $(S=2)$, the SinRef-7p model which take into account the transverse normal effect yields very accurate results for both frequencies and mode shapes. Nevertheless, for the thin beam, it seems that the Sin-c model presents a good compromise between the accuracy and the computational cost.

\section{A. Matrix expression for the weak form}

The expressions of the strains can be described using a matrix notation:

$$
\begin{aligned}
& {[\varepsilon]=\left[F_{S}(z)\right]\left[\mathscr{E}_{S}\right]}
\end{aligned}
$$

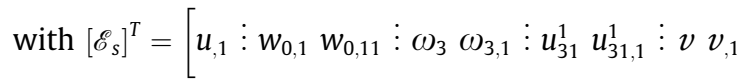

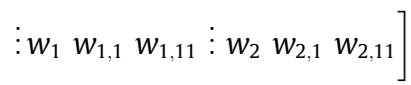

and $\left[F_{s}(z)\right]$ depends on the normal coordinate $z$.

From the weak form of the boundary value problem Eq. (2), and using Eq. (A.1), an integration throughout the cross section is performed analytically in order to obtain an unidimensional formulation. Therefore, the first left term of Eq. (2) can be written under the following form:

$$
\begin{gathered}
\int_{\mathscr{B}}\left[\varepsilon\left(\vec{u}^{*}\right)\right]^{T}[\sigma(\vec{u})] d \mathscr{B}=\int_{0}^{L}\left[\mathscr{E}_{s}^{*}\right]^{T}[k]\left[\mathscr{E}_{s}\right] d x_{1} \text { with } \\
{[k]=\int_{\Omega}\left[F_{s}(z)\right]^{T}[C]\left[F_{S}(z)\right] d \Omega}
\end{gathered}
$$

where $[C]$ is the constitutive law given in Section 2.1.1.

In Eq. (A.2), the matrix $[k]$ is the integration throughout the cross section of the beam material characteristics.

\section{References}

[1] Basset $A B$. On the extension and flexure of cylindrical and spherical thin elastic shells. Philos Trans Roy Soc (London) Ser A 1890;181:433-80.

[2] Tanigawa Y, Murakami H, Ootao Y. Transient thermal stress analysis of a laminated composite beam. J Therm Stress 1989;12:25-39.

[3] Nabi SM, Ganesan N. A generalized element for the free vibration analysis of composite beams. Compos Struct 1994;51(1):607-10.

[4] Eisenberger M, Abramovich H, Shulepov O. Dynamic stiffness analysis of laminated beams using a first order shear deformation theory. Compos Struct 1995;31:265-71.

[5] Teboub Y, Hajela P. Free vibration of generally layered composite beams using symbolic computations. Compos Struct 1995;33:123-34.

[6] Yildirim V. Effect of the longitudinal to transverse moduli ratio on the in-plane natural frequencies of symmetric cross-ply laminated beams by the stiffness method. Compos Struct 2000;50:319-26.

[7] Chakraborty A, Roy Mahapatra R, Gopalakrishnan S. Finite element analysis of free vibration and wave propagation in asymmetric composite beams with structural discontinuities. Compos Struct 2002;55:23-36.

[8] Goyal VK, Kapania RK. A shear-deformable beam element for the analysis of laminated composites. Finite Elements Anal Des 2007;43:463-77.

[9] Jun L, Hongxing H, Rongying S. Dynamic finite element method for generally laminated composite beams. Int J Mech Sci 2008;50:466-80.

[10] Chandrashekhara K, Bangera KM. Free vibration of composite beams using a refined shear flexible beam element. Comput Struct 1992;43:719-27. 
[11] Aydogdu M. Vibration analysis of cross-ply laminated beams with general boundary conditions by Ritz method. Int J Mech Sci 2005:47:1740-55.

[12] Karama M, Afaq KS, Mistou S. Mechanical behaviour of laminated composite beam by the new multi-layered laminated composite structures model with transverse shear stress continuity. Int J Solids Struct 2003;40:1525-46.

[13] Marur SR, Kant T. Free vibration analysis of fiber reinforced composite beams using higher order theories and finite element modelling. J Sound Vib 1996;194:337-51.

[14] Murthy MVVS, Roy Mahapatra D, Badarinarayana K, Gopalakrishnan S. A refined higher order finite element for asymmetric composite beams. Compos Struct 2005;67(1):27-35.

[15] Soldatos KP, Elishakoff I. A transverse shear and normal deformable orthotropic beam theory. J Sound Vib 1992;155(3):528-33.

[16] Shi G, Lam KY. Finite element vibration analysis of composite beams based on higher-order beam theory. J Sound Vib 1999;219:707-21

[17] Kant T, Marur SR, Rao GS. Analytical solution to the dynamic analysis of laminated beams using higher order refined theory. Compos Struct 1998;40(1):1-9.

[18] Kameswara Rao M, Desai YM, Chitnis MR. Free vibrations of laminated beams using mixed theory. Comput Struct 2001;52:149-60.

[19] Matsunaga H. Vibration and buckling of multilayered composite beams according to higher order deformation theories. J Sound Vib 2001;246(1):47-62.

[20] Zhen W, Wanji C. An assessment of several displacement-based theories for the vibration and stability analysis of laminated composite and sandwich beams. Compos Struct 2008;84:337-49.

[21] Subramanian P. Dynamic analysis of laminated composite beams using higher order theories and finite elements. Compos Struct 2006;73:342-53.

[22] Rao MK, Desai YM, Chitnis MR. Free vibrations of laminated beams using mixed theory. Compos Struct 2001;52:149-60.

[23] Chen WQ, Lv CF, Bian ZG. Elasticity solution for free vibration of laminated beams. Compos Struct 2003;62:75-82.

[24] Heller RA, Swift GW. Solutions for the multilayer timoshenko beam. In: Report N VPI-E-71-12. Virginia Polytechnic Institute, Blacksburg, VA; 1971

[25] Swift GW, Heller RA. Layered beam analysis. J Eng Mech ASCE $1974 ; 100: 267-82$

[26] Srinivas S. A refined analysis of laminated composites. J Sound Vib 1973:495-507

[27] Whitney JM. The effect of transverse shear deformation in the bending of laminated plates. J Comput Mater 1969;3:534-47.

[28] Pagano NJ. Exact solutions for composite laminates in cylindrical bending. J Comput Mater 1969;3:398-411.

[29] Shimpi RP, Ainapure AV. A beam finite element based on layerwise trigonometric shear deformation theory. Compos Struct 2001;53:153-62.

[30] Tahani M. Analysis of laminated composite beams using layerwise displacement theories. Compos Struct 2007;79(4):535-47.

[31] Lee C-Y, Liu D, Lu X. Static and vibration analysis of laminated composite beams with an interlaminar shear stress continuity theory. Int J Num Meth Eng 1992;33:409-24

[32] Ramtekkar GS, Desai YM, Shah AH. Natural vibrations of laminated composite beams by using mixed finite element modelling. J Sound Vib 2002;257:635-51.

[33] Plagianakos TS, Saravanos DA. High-order layerwise mechanics and finite element for the damped dynamic characteristics of sandwich composite beams. Int J Solids Struct 2004;41:6853-71.

[34] Baber TT, Maddox RA, Orozco CE. A finite element model for harmonically excited viscoelastic sandwich beams. Comput Struct 1998;66:105-13.

[35] Bekuit J-JRB, Oguamanam DCD, Damisa O. A quasi-2D finite element formulation for the analysis of sandwich beams. Finite Elements Anal Des 2007;43:1099-107.

[36] Banerjee JR, Sobey AJ. Dynamic stiffness formulation and free vibration analysis of a three-layered sandwich beam. Int J Solids Struct 2005;42:2181-97.

[37] Ambartsumyan SA. Theory of anisotropic plates. In: Cheron T, Ashton JE editors. Technomic Publishing Co.; 1969 [translated from russian].

[38] Di Sciuva M. Bending, vibration and buckling of simply supported thick multilayered orthotropic plates: an evaluation of a new displacement model. J Sound Vib 1986;105:425-42.

[39] Bhaskar K, Varadan TK. Refinement of higher-order laminated plate theories. AIAA J 1989;27:1830-1.

[40] Cho M, Parmerter R. Efficient higher-order composite plate theory for general lamination configurations. AIAA J 1993;31:1299-306.

[41] Averill RC, Yip YC. Thick beam theory and finite element model with zig-zag sublaminate approximations. AIAA J 1996;34(8):1627-32.

[42] Aitharaju VR, Averill RC. $C^{0}$ zig-zag finite element for analysis of laminated composite beams. J Eng Mech ASCE 1999;125:323-30.
[43] Di Sciuva M, Icardi U. Numerical assessment of the core deformability effect on the behavior of sandwich beams. Compos Struct 2001:52:41-53.

[44] Gaudenzi P, Barboni R, Mannini A. A finite element evaluation of single-layer and multi-layer theories for the analysis of laminated plates. Compos Struct 1995;30:427-40

[45] Gherlone M, Di Sciuva M. Thermo-mechanics of undamaged and damaged multilayered composite plates: a sub-laminates finite approach. Comput Struct 2007;81:125-36.

[46] Kapuria S, Dumir PC, Ahmed A. An efficient higher order zigzag theory for composite and sandwich beams subjected to thermal loading. Int J Solids Struct 2003;40:6613-31.

[47] Carrera E. Historical review of zig-zag theories for multilayered plates and shells. Appl Mech Rev 2003;56(3):287-308.

[48] Noor AK, Burton WS. Assessment of computational models for multilayered composite shells. Appl Mech Rev 1990;43(4):67-97.

[49] Reddy JN. Mechanics of laminated composite plates - theory and analysis. Boca Raton (FL): CRC Press; 1997.

[50] Carrera E. Theories and finite elements for multilayered, anisotropic, composite plates and shells. Arch Comput Meth Eng 2002;9:87-140.

[51] Zhang YX, Yang $\mathrm{CH}$. Recent developments in finite elements analysis for laminated composite plates. Compos Struct 2009;88:147-57.

[52] Mittelstedt C, Beckerm W. Free-edge effects in composite laminates. Appl Mech Rev 2007;60:217-44

[53] Kant T, Swaminathan K. Estimation of transverse/interlaminar stresses in laminated composites - a selective review and survey of current developments. Compos Struct 2000;49:65-75.

[54] Kapania RK, Raciti S. Recent advances in analysis of laminated beams and plates, part II: vibrations and wave propagation. AIAA J 1989;27:935-46.

[55] Ghugal YM, Shimpi RP. A review of refined shear deformation theories for isotropic and anisotropic laminated beams. J Reinf Palst Compos 2001;20:255-72.

[56] Touratier M. A generalization of shear deformation theories for axisymmetric multilayered shells. Int J Solids Struct 1992;29:1379-99.

[57] Ganapathi M, Patel BP, Polit O, Touratier M. A C ${ }^{1}$ finite element including transverse shear and torsion warping for rectangular sandwich beams. Int J Num Meth Eng 1999;45:47-75.

[58] Carrera E, Brischetto E. Analysis of thickness locking in classical, refined and mixed multilayered plate theories. Compos Struct 2008;82:549-62.

[59] Li X, Liu D. Generalized laminate theories based on double superposition hypothesis. Int J Num Meth Eng 1997;40:1197-212.

[60] Vidal P, Polit O. A family of sinus finite elements for the analysis of rectangular laminated beams. Compos Struct 2008;84:56-72. doi:10.1016 j.compstruct.2007.06.009.

[61] Touratier M. An efficient standard plate theory. Int J Eng Sci 1991:29:901-16.

[62] Dau F, Polit O, Touratier M. $C^{1}$ plate and shell finite elements for geometrically nonlinear analysis of multilayered structures. Comput Struct 2006;84:1264-74.

[63] Polit O, Touratier M. A multilayered/sandwich triangular finite element applied to linear and nonlinear analysis. Compos Struct 2002;58:121-8.

[64] Touratier M. A refined theory of laminated shallow shells. Int J Solids Struct 1992;29(11):1401-15.

[65] Vidal P, Polit O. A thermomechanical finite element for the analysis of rectangular laminated beams. Finite Elements Anal Des 2006:42(10):868-83.

[66] Vidal P, Polit 0 . Assessment of the refined sinus model for the non-linear analysis of composite beams. Compos Struct 2009;87:370-81. doi:10.1016/ j.compstruct.2008.02.007.

[67] Sze KY, Chen R, Cheung YK. Finite element model with continuous transverse shear stress for composite laminates in cylindrical bending. Finite Elements Anal Des 1998;31:153-64.

[68] Wu Z, Chen R, Chen W. Refined laminated composite plate element based on global-local higher-order shear deformation theory. Compos Struct 2005;70(2):135-52

[69] Zhen W, Wanji C. Refined global-local higher-order theory and finite element for laminated plates. Int J Num Meth Eng 2007;69:1627-70.

[70] Vidal P, Polit O. A refined sinus finite element with transverse normal deformation for the analysis of laminated beams under thermomechanical loads. J Mech Mater Struct 2009;4(6):1127-55.

[71] Polit O, Touratier M, Lory P. A new eight-node quadrilateral shear-bending plate finite element. Int J Num Meth Eng 1994;37:387-411.

[72] Karama M, Abou Harb B, Mistou S, Caperaa S. Bending buckling and free vibration of laminated composite with a transverse shear stress continuity model. Compos Part B: Eng J 1998;29:223-34.

[73] Kapuria S, Dumir PC, Jain NK. Assessment of zigzag theory for static loading, buckling, free and forced response of composite and sandwich beams. Compos Struct 2004;64:317-27.

[74] Ansys I. Ansys theoretical manual. Swanson Analysis Inc.; 1986. 